\section{Children of Divorce}

The Divorce Reform Act 1969 came into force on New Year's Day. Irretrievable breakdown of marriage thus becomes the sole ground of divorce, a situation increasingly recognized and acted upon by some judges in the past few years. The number of divorces in the immediate future is expected to rise and may far exceed the 60,000 recorded in the post-war peak of 1947. In fact, the number has already more than doubled since the trough of 22,000 divorces and annulments in 1958. Of the 45,000 women divorced in 1968 more than 12,000 were childless, ${ }^{1}$ but the remainder had a total of about 60,000 children of all ages. No doubt great efforts are made by the High Court to safeguard the interests of these children, to secure financial provision for them, and to arrange for their welfare, but no court can compensate a child for absence of one of its parents.

Few medical and sociological reports in Britain have paid attention to the effect of divorce on the children of the marriage. This is in contrast to the swollen literature on the "broken-home" situation in general, its relation to neurosis and delinquency, and the many articles on death of a parent ${ }^{2} 3$ in childhood. As Lady Wootton has said," "The sociological study of divorce, apart from a few American investigations, has remained comparatively unfashionable." Divorce is far commoner in the United States. The number has doubled each year since 1940 and by 1967 had reached 523,000, involving 700,000 children under 18 each year.

The author of a recent paper, ${ }^{5} \mathrm{~J}$. F. McDermott studied the records of 1,487 children up to the age of 14 seen at a university psychiatric clinic in Michigan. He excluded 22 whose parents were separated but not divorced, and then compared the 116 children of divorced parents with the remainder. He found that, as compared with the remainder of the children, those with divorced parents were more often only children, had a shorter duration of symptoms, and that "acting out" and poor behaviour at school and at home predominated over neurotic symptoms. Delinquent and predelinquent behaviour and depression, both overt and masked, distinguished this group from the controls.

The second part of the paper is an impressionistic study from the case records of children directly involved in the divorce. McDermott found overt depressive symptoms in one-third of the patients and covert depression too-for example, accident proneness, lack of concern with safety, complaints of fatigue, and depression alternating with aggression. He found several children who regarded themselves quite unjustly as responsible for the divorce and blamed themselves. Quarrels between the parents over maintenance payments after the divorce often upset the child further, as did, of course, continuing battles over custody and visiting and the parents' continuing need to hurt each other. Problems of identification were encountered when children identified themselves with the missing parent or themselves ran away, and they did so too when the mother cast the child in the role of the missing husband.

As the author himself admits, this study has defects. It was retrospective; some important material was missing from the case records; and the controls often came from unstable families themselves. He utters cautions about generalizing from the findings in these sick children to other children of divorce who are not psychiatric patients. An earlier study by the same: author ${ }^{6}$ reports that 10 out of 16 ordinary nursery school children of divorced couples showed dramatic changes in behaviour at the time of divorce. Shock, anger, depression, denial, destructiveness, and regression were observed. Often this disturbance in the child led to inquiries that showed that the mother had concealed the fact of divorce from the schoolthough not from the child.

A further clue to the frequency of disturbance in the children of divorce appears in another American study. ${ }^{7}$ Of 148 consecutive divorces coming before a family court 105 involved children. Of these, $31 \%$ showed continuing strife between the partners about money, custody, and visiting. It is clear that in these cases the couples remained embattled and the children were used as pawns. Occasionally it was the children who were stirring up trouble in order to get their parents to become reunited. Divorce is only the culmination of a prolonged family upheaval, and the upheaval can continue long after the divorce. Indeed it sometimes seems to affect the next generation. McDermott's studies show clearly that the fact of physical separation from one parent, which is the usual consequence of divorce, imposes on children an acute extra stress. In an uncertain proportion of cases this stress leads to depression, grief reactions, "acting out" behaviour, and aberrations of identification.

It is sometimes thought better for a child to live with one divorced parent than with two unhappily married parents. The few studies mentioned here show that this comfortable doctrine of "get on or get out" needs looking at again. Perhaps the other stereotype, the wife who says that she will stick it out until the children are grown up, could be the wiser.

\footnotetext{
The Registrar General's Statistical Review of England and Wales for the Year 1968, Part II, Tables, Population. London, H.M.S.O., 1970.

Birtchnell, J., British fournal of Psychiatry, 1970, 116, 281.

3 Dennehy, C., British fournal of Psychiatry, 1966, 112, 1049.

Wootton, B., Social Science and Social Pathology. London, Allen and Unwin, 1959.

5 McDermott, J. F., Archives of General Psychiatry, 1970, 23, 421.

- McDermott, J. F., American fournal of Psychiatry, 1968, 124, 1424.

Westman, J. C., Cline, D. W., Swift, W. J., and Kramer, D. A., Archives of General Psychiatry, 1970, 23, 416.

${ }^{8}$ Daily Sketch, quoted by Mr. Justice Scarman, Medico-Legal fournal, 1966, 34, 11 .
}

\section{Chlorpropamide in Diabetes Insipidus}

Hypofunction of endocrine glands is usually treated by replacement of the hormone. In some diseases, such as Addison's disease or hypothyroidism, giving the hormone by mouth is sufficient, while in others, such as diabetes mellitus, injections are necessary because of the protein nature of the hormone. Good results have also been obtained with substances which are not hormones but can nevertheless correct or ameliorate the endocrine hypofunction: vitamin D therapy in hypoparathyroidism and sulphonylureas in diabetes mellitus are two notable examples.

In the treatment of diabetes insipidus replacement therapy with vasopressin either by injection or as a snuff remains the mainstay of treatment. But over the last 30 years several substances with little or no chemical similarity to vasopressin have been reported to benefit patients with this disease. In 1932 , for instance, aminopyrine ${ }^{1}$ was shown to decrease the urine volume in patients with diabetes insipidus, but its toxic effects precluded a full assessment of its usefulness.

As a result of in vitro studies in which paracetamol was found to increase the flow of water across the bladder wall of 
the toad Bufo marinus it was given in doses of $1 \cdot 2-2 \cdot 4 \mathrm{~g}$ per day to three patients with diabetes insipidus. In each the volume of urine and clearance of free water fell. ${ }^{2}$ Thiazide diuretics have also been given, with varying success, to patients with diabetes insipidus. ${ }^{3}$ The mechanism of this effect has never been wholly understood, but it is probably related to their natriuretic action. Thiazides are probably of greater use for patients with nephrogenic diabetes insipidus who are resistant to vasopressin.

The most effective drug apart from vasopressin for the treatment of diabetes insipidus is the sulphonylurea, chlorpropamide. Like many other important advances in clinical therapeutics this was made by chance-or rather by the error of a patient, a 37-year-old man in Rio de Janiero who, believing he was suffering from diabetes mellitus, prescribed chlorpropamide for himself. ${ }^{4}$ So successful were the results that his physicians gave chlorpropamide to four other patients, two with nephrogenic diabetes insipidus and two with the idiopathic vasopressin-dependent variety of the disease. Both patients with the latter type responded but neither with the former type.

In the successful cases there was a considerable fall in the urine volume and a decrease in both the urine osmolarity and free water clearance, but no change in the osmolar clearance or glomerular filtration rate. Thus the results were very like those obtained with vasopressin. In their original report F. Arduino and his colleagues ${ }^{4}$ postulated that these changes might be due, firstly, to chlorpropamide directly stimulating the release of antidiuretic hormone from the pituitary, or secondly to restoring the response of insensitive osmoreceptors to normal stimuli, or thirdly to a direct action of the drug on the kidney. Some support for the first of these explanations comes from the work of B. Ettinger and P. H. Forsham, ${ }^{5}$ though they made no measurements of circulating levels of antidiuretic hormone. Against this theory is the observation ${ }^{6}$ that patients with familial congenital diabetes insipidus, who are thought to have no antidiuretic hormone in the posterior pituitary, respond to chlorpropamide. Likewise the second explanation, that of restoration of osmoreceptor sensitivity, seems untenable, since delayed excretion of water after water loading is seen in patients with diabetes insipidus on chlorpropamide. The idea that a drug structurally dissimilar to the natural hormone may act in the same way as the hormone itself is puzzling. J. H. Mahoney and A. D. Goodman ${ }^{7}$ have tried to explain this paradox by suggesting that $3^{\prime}, 5^{\prime}$ adenosine monophosphate (cyclic AMP) mediates the action of vasopressin and of chlorpropamide on the pancreas in diabetes mellitus and on the kidney in diabetes insipidus. It seems unlikely that the action of chlorpropamide in diabetes insipidus is related to its hypoglycaemic action, because cther agents that lower the level of the blood sugar, such as insulin, have no such effect.

Chlorpropamide has an important therapeutic role in the treatment of vasopressin-dependent diabetes insipidus, but not in the treatment of the nephrogenic (vasopressin-resistant) form of the disease. The side effects of vasopressin-intestinal discomfort, headache, rhinitis, and, more seriously, angina in patients with ischaemic heart disease-can be so unpleasant that some patients prefer to put up with the symptoms of the disease rather than take vasopressin. It is for these patients that chlorpropamide is of greatest use.

The effectiveness of this drug has been challenged, however. A. G. Hocken and D. Longson ${ }^{8}$ found that two out of three patients with idiopathic diabetes insipidus showed no response to $250 \mathrm{mg}$ or $500 \mathrm{mg}$ chlorpropamide given by mouth. In two patients with both anterior and posterior pituitary disease chlorpiopamide therapy has been found ineffective. ${ }^{9}$ Furthermore, several reports ${ }^{10} 11$ have stressed that the hypoglycaemia produced by chlorpropamide may limit its usefulness. One patient, an eight-year-old boy whose diabetes insipidus had been well controlled with parenteral vasopressin, had hypoglycaemic convulsions when chlorpropamide was substituted.

Several interesting pharmacological points are raised by the use of chlorpropamide in diabetes insipidus. Its effect is dose-dependent, and several days elapse before the response is optimum. This is presumably related to the achievement of an adequate plasma concentration of the drug. The effect can last for as long as 10-15 days after withdrawal of the drug; though chlorpropamide lasts longer in the plasma (half-life some 30-40 hours) than other sulphonylureas, this duration of effect is remarkable. Finally, why this drug and no other sulphonylurea should be effective is peculiar. The biguanide, metformin, another oral antidiabetic drug, has also been found effective in patients with diabetes insipidus, ${ }^{11}$ but it has not been investigated so thoroughly as chlorpropamide.

Apart from its therapeutic interest, the manner of chlorpropamide's action may, when it is elucidated, shed further light on the molecular basis of diabetes insipidus.

Scherf, D., Wiener Archiv für innere Medizin und deren Grenzgebiete, 1932, 22, 457.

Nusynowitz, M. L., and Forsham, P. H., American fournal of Medical Science, 1966, 252, 429.

${ }^{3}$ Crawford, J. D., and Kennedy, G. C., Nature, 1959, 183, 891

Arduino, F., Ferraz, F. P. J. V., Rodrigues, J., fournal of Clinical Endocrinology, 1966, 26, 1325.

Ettinger, B., and Forsham, P. H., fournal of Clinical Endocrinology and Metabolism, 1970, 31, 552.

Meinders, A. E., Touber, J. L., and de Vries, L. A., Lancet, 1967, 2, 544. Mahoney, J. H., and Goodman, A. D., New England Fournal of Medicine, $1968,279,1191$.

8 Hocken, A. G., and Longson, D., British Medical fournal, 1968, 1, 355 Kumar, R. S., Sotow, W. W., and Cole, V. W., Lancet, 1969, 1, 577.

Ehrlich, R. M., and Kooh, S. W., Lancet, 1969, 1, 890.

1 Sack, J., and Katznelson, D., Lancet, 1969, 1, 729.

2 Katsuki, S., and Ito, M., Lancet, 1966, 2, 530.

\section{Marginal Ulceration of the Cornea}

A painful red eye is a common diagnostic problem. Apart from minor foreign bodies, the usual causes are conjunctivitis, anterior uveitis (iritis), acute closed-angle glaucoma, and keratitis. It is this last cause which receives the least attention, particularly as specialized equipment (such as a slit lamp) is often required to establish the diagnosis. Nevertheless, some forms of keratitis are easy to recognize with nothing more than a torch, and one of these is simple marginal ulceration of the cornea. This by no means uncommon condition presents as a painful red eye with a round ulcer overlying an obvious grey to white infiltrate. The ulcer is about $1 \mathrm{~mm}$ in diameter with a clear zone of cornea separating it from the limbus, and the conjunctiva is injected locally. The lesion may clear spontaneously in about a week but it is often surprisingly painful and it frequently recurs.

A. H. Chignell and his colleagues have recently reported on 84 patients with marginal ulceration of the cornea seen over a period of one year. ${ }^{1}$ They point out how closely the symptoms resemble those of a corneal foreign body. Pathogenic staphylococci have long been suspected of being a cause of this condition, and in this study almost a third of the patients were 